\title{
Efficacy, Safety, Cost, and Clinical Outcomes After the Switch to Generic Rosuvastatin Compared with Consistent Brand-Name Atorvastatin Treatment.
}

Mu-shiang Huang

National Cheng Kung University Hospital

Chun-I Wu

Kuo General Hospital

Pei-Fang Su

National Cheng Kung University

Ping-Yen Liu ( $\nabla$ larry@mail.ncku.edu.tw )

National Cheng Kung University

Research Article

Keywords: statin, cholesterol, generic, hyperlipidemia, HMG-CoA reductase

Posted Date: December 23rd, 2021

DOl: https://doi.org/10.21203/rs.3.rs-1061000/v2

License: (c) (i) This work is licensed under a Creative Commons Attribution 4.0 International License.

Read Full License 
2 Efficacy, safety, cost, and clinical outcomes after the switch to generic rosuvastatin

3 compared with consistent brand-name atorvastatin treatment.

4

\section{Authors}

6 Mu-shiang, Huang, MD, MS ${ }^{1,4, *}$, Chun-I, Wu, MD ${ }^{2, *}$, Pei-Fang, Su, $\mathrm{PhD}^{4}$, Ping-Yen Liu, MD, $\mathrm{PhD}^{1,3}$

$8 \quad{ }^{1}$ Division of Cardiology, Department of Internal Medicine, National Cheng Kung University Hospital,

9 College of Medicine, National Cheng Kung University, Tainan, Taiwan.

$0 \quad{ }^{2}$ Division of Cardiology, Department of Internal Medicine, Kuo general hospital

$1{ }^{3}$ Institute of Clinical Medicine, College of Medicine, National Cheng Kung University, Tainan, Taiwan.

$2 \quad{ }^{4}$ Department of Statistics, College of Management, National Cheng Kung University, Tainan, Taiwan.

$3 \quad{ }^{*}$ Contributed equally as first author

4 Word count: 2490

5 Corresponding Author: Ping-Yen Liu

6 Ping-Yen Liu, MD, PhD

7 Professor of Medicine

8 Division of Cardiology, Department of Internal Medicine, National Cheng Kung University Hospital, College of

9 Medicine, National Cheng Kung University

0138 Sheng-Li Road, Tainan 704, Taiwan

1 TEL: +886-6-2353535, ext.: 4602

2 E-mail: larry@mail.ncku.edu.tw 
1 Abstract

2 Background:

3 The efficacy, safety, and clinical outcomes for patients switch to generic rosuvastatin,

4 compared with patients taking other brand-name atorvastatin, is unclear.

5 Method:

6 We retrospectively collected electronic medical records from January 1,2013 , to

7 December 31, 2020, of patients who switched medication, because of hospital policy, from

8 brand-name to generic rosuvastatin after March 14, 2018. we only considered patients who

9 had taken the medication at least 1 year prior to and 1 year after that date. We also

0 collected records of patients who consistently used brand-name atorvastatin during the

1 same period. The efficacy of lipid control, potential adverse effects, clinical outcomes of

2 major cardiovascular events (MACE), and medical expenses were compared between the 2

3 groups. Propensity score matching (PSM) was conducted to balance potential cofounders.

4 Result:

5 After 1:1 PSM, 592 patients were enrolled in the rosuvastatin and atorvastatin groups,

6 and no significant difference was observed in their total cholesterol (TC) level difference

$7 \quad(-4.38 \pm 23.0$ vs. $-3.72 \pm 26.95 \mathrm{mg} / \mathrm{dL}, P=0.702)$, low-density lipoprotein (LDL-C) $(-2.38$

$8 \pm 19.89$ vs. $-2.42 \pm 23.63 \mathrm{mg} / \mathrm{dL}, P=0.976)$, or glycated hemoglobin $(-0.05 \% \pm 0.7 \%$ vs.

$9-0.08 \% \pm 0.76 \%, P=0.543)$. No significant differences were noted in their cumulative

$0 \quad$ MACE $(2.70 \%$ vs. $3.89 \%$, log-rank $P=0.265)$ after the switch date, and each person in the 
1 generic group had a $16 \%$ average reduction in their medical expenses.

\section{Conclusion:}

3 Switching to generic rosuvastatin led to comparable lipid-lowering efficacy, safety, and

4 clinical outcomes and fewer medical expenses compared with consistently using brand-name

5 atorvastatin.

6 Keyword: statin, cholesterol, generic, hyperlipidemia, HMG-CoA reductase 
3 medication used to treat patients with hyperlipidemia for both primary and secondary

4 prevention, according to their individual risks with regard to underlying comorbidities,

5 family histories, age, and their calculated 10 -year risk of fatal CVD ${ }^{1,2}$. Both rosuvastatin and

6 atorvastatin are categorized as high-potency lipid-lowering agents, and for each $1 \mathrm{mmol} / \mathrm{L}$

$7 \quad(38.67 \mathrm{mg} / \mathrm{dL})$ reduction of LDL-C by statin, they may reduce major vascular events by $22 \%^{2}$.

$8 \quad$ Generic medication represents opportunities for patients who cannot afford essential

9 brand-name medications and to reduce public health expenses. Generic medications must

0 have identical active ingredients that produce the same or acceptable pharmaceutical

1 results as the referenced brand-name medication, with respect to pharmacokinetic and

2 pharmacodynamic properties. According to a report by Warraich et al., from 2012 to 2014,

3 the availability of generic atorvastatin led to a $28 \%$ reduction in atorvastatin-associated

4 expenditure in the United States ${ }^{3}$. Manzoli et al. performed a meta-analysis of studies

5 comparing generic and brand-name atorvastatin and simvastatin, and they demonstrated a

6 similar aggregated effect size of clinical efficacy in terms of soft outcomes $(0.04,95 \% \mathrm{Cl}$ :

$7-0.10$ to 0.18$)$ and safety in mild to moderate adverse events $(-0.06,95 \% \mathrm{Cl}:-0.40$ to 0.27$)$

$8 \quad\left({ }^{4}\right)$. Using data from a large retrospective cohort, Gao et al. also reported that major adverse

9 cardiovascular events (MACE) did not differ significantly between generic and brand-name

0 statin (pitavastatin, atorvastatin, pravastatin, simvastatin, or fluvastatin) users ${ }^{5}$. However, 
1 another study indicated a lower rate of LDL-C target achievement (0.87, 95\% $\mathrm{Cl}: 0.80-0.95)$

2 among patients who used generic atorvastatin or simvastatin that may be translated to an

3 increased rate of cardiovascular incidents (HR: $1.31,95 \% \mathrm{Cl}: 1.15-1.50)^{6}$.

$4 \quad$ Nevertheless, evidence gaps persist. First, in real-world practice, government policies

5 rather than physicians may mandate the switch from brand-name to generic medication.

6 Therefore, patients are concerned whether the switch leads to poorer clinical outcomes

7 compared with other medications not being changed. Second, to our knowledge, clinical

8 evidence remains unavailable on generic rosuvastatin usage. Therefore, this study provides

9 clinical evidence comparing the efficacy, safety, clinical outcomes, and medical expenses

0 between a switch to generic rosuvastatin and consistent brand-name statin. 


\section{Methods}

\section{Ethical statement}

This study was conducted in accordance with the Declaration of Helsinki, waives the

4 requirement to obtain informed consent, and approved by the Institutional Review Board of

5 National Cheng Kung University Hospital (B-ER-110-134).

6 Study design

$7 \quad$ We retrospectively collected data from January 1,2013 , to December 31,2020 , from

8 the cardiovascular databank of National Cheng Kung University Hospital. Because of

9 medicine contract, all brand-name rosuvastatin (Crestor $10 \mathrm{mg}$, Shionogi \& Co., Ltd.) was

0 switched to generic medication (Roty $10 \mathrm{mg}$, China Chemical \& Pharmaceutical Co., Ltd.)

1 after 14 March 2018, the switch index date in this study. We enrolled patients who had

2 received brand-name rosuvastatin for more than 1 year before and after the switch index

3 date. Patients who used brand-name atorvastatin (Lipitor $40 \mathrm{mg}$, Pfizer) within the same

4 timeframe served as the control group.

5 Data collection

6 From the cardiovascular electronic medical record databank, we collected information

7 on all patients' clinical diagnoses, underlying comorbidities, and medication histories. We

8 also collected their laboratory data, including total cholesterol (TC), LDL-C, HDL-C,

9 triglyceride (TG); alanine aminotransferase (ALT) and glycated hemoglobin (HbA1c) levels;

0 and estimated glomerulus filtration rates (eGFR) in the 1 year both before and after the

1 index date. Blood sampling frequency and timing were determined by the clinical physician. 
1 This databank was created according to the study protocol of Artificial Intelligence with

2 Deep Learning and Genes on Cardiovascular Disease, with ClinicalTrials.gov Identifier

3 NCT03877614. Two cardiovascular physicians validated the database by manually reviewing

4 records highlighting 4 random traits, such as baseline characteristics, comorbidities, or

5 medications, for each of 200 randomly-selected patients. The accuracy rate for all traits was

$699.12 \%(793 / 800)^{7}$. The primary endpoint of this study was MACE, defined as a composite

7 endpoint of all-cause mortality, acute myocardial infarction, and ischemic stroke. The

8 secondary endpoints were each individual event. The expense of medications was

9 calculated based on public price announced by National Health Insurance Administration

0 Ministry of Health.

1 Statistics

2 Patients were divided into 2 groups: generic-shift rosuvastatin and brand-name

3 atorvastatin, and 1:1 propensity score matching (PSM) was performed to adjust for

4 confounders including age, sex and underlying comorbidities. Continuous variables are

5 presented as the mean $\pm S D$, the Student's $t$ test was performed to examine the difference

6 between groups, and the paired $t$ test was performed before and after the medication

7 switch. Dichotomous data are presented as numbers (percentages), and the chi-square test

8 was performed to examine differences. Kaplan-Meier survival analysis was employed to

9 compare cumulative endpoints between groups, and the log-rank test was used to examine

0 statistical significance. We performed PSM with Matchlt (version 4.2.0), and all other 
1 analyses were conducted with $\mathrm{R}$ (version 4.0.1). 


\section{Results}

\section{Population}

$3 \quad$ From January 2013 to December 2020, 12969 patients received brand-name

4 atorvastatin, and 2926 patients received brand-name rosuvastatin in a switch from the

5 generic brands. Of those patients, 3094 and 1015 had already been using brand-name

6 atorvastatin and rosuvastatin respectively, for more than 1 year prior to the index date. The

7 brand-name atorvastatin group consisted of 2129 (57.8\% male, mean age $68.5 \pm 11.8$ years)

8 patients, and the generic group consisted of 600 patients $(52.7 \%$ male, mean age $65.2 \pm 11.8$

9 years) who had been using medication consistently for more than 1 year after the index date.

$0 \quad$ After 1:1 PSM, $592(53.7 \%$ male, mean age $65.4 \pm 12.1$ years $)$ patients remained in the

1 brand-name atorvastatin group, and 592 (53.4\% male, mean age $65.2 \pm 11.8$ years) patients

2 were in the generic-switch rosuvastatin group. (Table 1 and Figure 1)

$3 \quad$ Efficacy and safety

$4 \quad$ After PSM, for efficacy in lipid-lowering effects, both generic-switch rosuvastatin and

5 brand-name atorvastatin groups exhibited comparable lower TC $(-4.38 \pm 23.00 \mathrm{mg} / \mathrm{dL}$ vs.

$6 \quad-3.72 \pm 26.95 \mathrm{mg} / \mathrm{dL}, P=0.702)$, LDL-c $(-2.38 \pm 19.89 \mathrm{mg} / \mathrm{dL}$ vs. $-2.42 \pm 23.63 \mathrm{mg} / \mathrm{dL}, P$

$7=0.976)$, and HDL-c $(-1.23 \pm 7.93 \mathrm{mg} / \mathrm{dL}$ vs. $-1.60 \pm 7.62 \mathrm{mg} / \mathrm{dL}, P=0.559)$ levels after

8 the medication switch index date. Patients exhibited similar differences in $\mathrm{HbA} 1 \mathrm{c}(-0.05 \% \pm$

$90.7 \%$, vs. $-0.08 \% \pm 0.76 \%, P=0.543)$, ALT $(-0.58 \pm 19.87 \mathrm{U} / \mathrm{L}$ vs. $-0.14 \pm 44.92 \mathrm{U} / \mathrm{L}, P=$

$0 \quad 0.841)$, and eGFR $\left(-1.36 \pm 6.95 \mathrm{~mL} / \mathrm{min} / 1.73 \mathrm{~m}^{2}\right.$ versus $-1.37 \pm 8.14 \mathrm{~mL} / \mathrm{min} / 1.73 \mathrm{~m}^{2}, P=$ 
1 0.988) levels before and after the switch index date (Table 2 and Figure 3).

\section{Outcome}

3 Between the generic-switch rosuvastatin and brand-name atorvastatin groups, no

4 significant differences were observed in the primary endpoint $(2.70 \%$ vs. $3.89 \%, P=0.265)$

5 after the switch index date with a median follow-up time of 820 and 822.5 days, respectively,

6 or after the medication initialization date $(4.56 \%$ vs. $6.59 \%, P=0.664)$ with a median

7 follow-up time of 1803.5 and 2359 days, respectively. No significant differences were noted

8 in any of the individual secondary endpoints (Table 3 and Figure 2).

\section{$9 \quad$ Expenses}

0 In 2019, the average cost for generic rosuvastatin and brand-name atorvastatin was

1 NT\$452.50 and NT\$539.30 per person. The annual expenditure for all patients was

2 NT\$9,350,854.90 and NT\$29,159,591.40, respectively. (Figure 4)

3

4 Discussion

5 Results revealed that compared with the brand-name atorvastatin group, the group that

6 transitioned from brand-name to generic rosuvastatin had a comparable lipid-lowering

7 efficacy, no increase in hepatic toxicity or averaged $\mathrm{HbA} 1 \mathrm{c}$, and comparable clinical

8 outcomes. The generic-switch group exhibited lower medication expenses per person;

9 however, this group had lower persistence in the use of medication. To our knowledge, our

0 study is the first to obtain data on the switch to generic rosuvastatin.

1 Efficacy and safety 
2 vs. $2.64 \mathrm{mmol} / \mathrm{L}, P=0.923)$ and TC (4.71 vs. $4.68 \mathrm{mmol} / \mathrm{L}, P=0.583)$ levels and slightly

3 lower HDL-c levels (1.29 vs. $1.26 \mathrm{mmol} / \mathrm{L}, P=0.009)$ before and after the switch to generic

4 atorvastatin ${ }^{8}$. Our results are comparable to these findings because, although both groups

5 exhibited significantly lower levels of LDL-c, TC, and HDL-c, the differences were similar

6 and more likely to have resulted from cholesterol management goals and stricter monitoring.

7 This highlights the value of our study design: only when simultaneous ongoing treatments

8 are compared could we verify that medication was not the only factor to affect cholesterol

9 levels; in this manner, people are not misled to believe that the improved efficacy was a

0 result of generic medications (Table 2 and Figure 3).

1 No significant differences were noted in potential side effects of statin, such as new

2 onset diabetes mellitus and hepatotoxicity. In meta-analysis studies by Kesselheim and

3 Manzoli et al., 6 comparison studies between generic and brand-name medications were

4 enrolled. These studies mostly employed cross-over designs examining simvastatin and

5 atorvastatin and revealed no significant differences in the clinical efficacy of LDL control

6 (effect size: $0.04,95 \%$ CI: -0.10 to 0.18 ) or any mild or moderate adverse events (effect

7 size: $-0.06,95 \% \mathrm{CI}:-0.40$ to 0.27$)^{4,9}$. Although these studies provided no data on generic

8 rosuvastatin, they support our results.

$9 \quad$ Clinical outcomes

$0 \quad$ Numerous studies have reported clinical outcome comparisons between initial 
1 treatments with generic and brand-name statins. Corrao et al. examined 13799 newly treated

2 patients with generic or brand-name simvastatin from Italy's health care system, and

3 discovered no difference in the risk of cardiovascular outcomes (HR: 1.06; 95\% CI: $0.83-$

$4 \quad 1.34)^{10}$. Gagne et al. examined the electronic data of American patients who were initially

5 treated with generic or brand-name statin (lovastatin, pravastatin, or simvastatin), with 6380

6 patients in each group. They discovered an $8 \%$ reduction in the rate of adverse clinical

7 outcomes in the generic group (HR: 0.92; 95\% CI: 0.86-0.99) ${ }^{11}$. Moreover, Gao et al.

8 conducted a Japanese cohort study with 14313 patients (post 1:1 PPM) in each group who

9 took generic or brand-name statin (atorvastatin, pravastatin, pitavastatin, simvastatin, or

0 fluvastatin), and found no significant differences in MACE outcomes (HR: 1.04; 95\% CI:

1 0.93-1.17). Additionally, Sicras-Mainar et al. examined a total of 13244 records of patients

2 from Spain who were initially treated with generic or brand-name statin (atorvastatin and

3 simvastatin). This study revealed a higher occurrence of major cardiovascular incidents in

4 generic group (HR: 1.31; 95\% CI: 1.15-1.50), and the authors stated a possible explanation

5 may be a lower (14\% reduction) medication consistency rate among the generic group ${ }^{6}$.

6 Despite the relatively heterogeneous results of previous studies, our results are

7 comparable to most of the results, with no significant differences in clinical outcomes from

8 the medication start and switch dates. Moreover, because studies have investigated the

9 effects of initial medication, rather than those that resulted from a switch, and lacked

0 rosuvastatin data, our study provided more evidence regarding the switch to generic 
1 rosuvastatin (Table 3 and Figure 2).

2 Medication persistence

3 In a comparison of 1-year persistence rates, Romanelli et al. reported lower persistence

4 in the generic than in the brand-name groups $(61.3 \%$ and $66.2 \%, P=0.021$, respectively),

5 and our study revealed similar results [59.1\% (600/1015) vs. 68.8\% (2129/3094), $P<0.001$,

6 respectively $^{12}$. The lower persistence rate in the generic-switch group may be attributed to

7 the medication switch having driven patients to search for facilities that provided their

8 original medication. Nevertheless, we conducted an analysis on patients with persistent

9 medication use, which was expected to have no influence on the interpretation. Notably,

0 studies have also revealed that the switch to other types of statin was frequently to less

1 potent medications that may also affect clinical outcomes ${ }^{12,13}$.

$2 \quad$ Medical expense

3 Although the efficacy of achieving controlled lipid levels was comparable between the

4 generic-switch and brand-name groups, the expense of statin use per person was

5 approximately $16.1 \%$ lower in the generic group than in the brand-name group (NT\$452.50

6 vs. NT \$539.30). This is consistent with the results obtained by Warraich et al., indicating a

$723 \%$ reduction (from NT $\$ 7.0$ to NT $\$ 5.4$ billion). Given the comparable efficacy and clinical

8 outcomes, they recommended using a generic substitute to reduce costs ${ }^{3}$. (Figure 4)

$9 \quad \underline{\text { Limitations }}$

$0 \quad$ Our study has several limitations. First, this was a single-center retrospective study 
1 enrolling people of primarily east-Asian ethnicities. Therefore, although our results are

2 comparable to those of global studies, their generalizability may be limited. Second, no

3 routine medical records were available regarding potential adverse effects of muscle pain or

4 creatine kinase levels that we could use for comparison. Third, longer follow-up periods after

5 the switch date may be required to measure cardiovascular outcomes. Although we analyzed

6 outcomes after the medication initiation and switch dates, long-term prognoses after the

7 switch date may require further investigation. Fourth, the medications in our study were

8 Crestor, Roty, and Lipitor, and the result may not be generalizable to other medications.

9

0 Conclusion

1 Patients who switched to generic rosuvastatin had comparable lipid-lowering efficacy,

2 safety, and clinical outcomes and lower medical expenses than patients who consistently

3 used brand-name atorvastatin.

4

5 
1 Declarations

2 Availability of data and materials

3 The datasets used and/or analysed during the current study are available from the

4 corresponding author on reasonable request.

5 Competing interests

6 The authors declare that they have no competing interests

7 Funding

8 This study was supported by grants 110-2314-B-006-090-MY3 and 109-2314-B-006-

9 068-MY2 from the Ministry of Science and Technology of Taiwan, grants D110-G2512 from

$0 \quad$ Higher Education Sprout Project, Ministry of Education to Headquarters of University

1 Advancement at National Cheng Kung University, and grants NCKUH-11002001 from

2 Clinical Research Center of National Cheng Kung University hospital

\section{Authors' contributions}

$4 \quad$ MSH conducted data collection, analyzing, tables and figures drafting; CIW did

5 manuscript writing; PFS supervised data analyzing; PYL provide the concept and source of

6 data.

7 Acknowledge

8 This manuscript was edited by Wallace Academic Editing. 


\section{Reference}

21 Grundy, S. M. et al. 2018 AHA/ACC/AACVPR/AAPA/ABC/ACPM/ADA/AGS/APhA/ASPC/NLA/PCNA

3 Guideline on the Management of Blood Cholesterol: A Report of the American College of Cardiology/American Heart Association Task Force on Clinical Practice Guidelines. Circulation 139, e1082-e1143, doi:10.1161/cir.0000000000000625 (2019).

62 Mach, F. et al. 2019 ESC/EAS Guidelines for the management of dyslipidaemias: lipid modification to reduce cardiovascular risk. Eur Heart J 41, 111-188, doi:10.1093/eurheartj/ehz455 (2020).

83 Warraich, H. J. et al. Trends in Use and Expenditures of Brand-name Atorvastatin After Introduction 9 of Generic Atorvastatin. JAMA Intern Med 178, 719-721, doi:10.1001/jamainternmed.2018.0990 0 (2018).

14 Manzoli, L. et al. Generic versus brand-name drugs used in cardiovascular diseases. Eur J Epidemiol 31, 351-368, doi:10.1007/s10654-015-0104-8 (2016).

35 Gao, J., Seki, T. \& Kawakami, K. Comparison of adherence, persistence, and clinical outcome of generic and brand-name statin users: A retrospective cohort study using the Japanese claims database. Journal of cardiology 77, 545-551, doi:10.1016/j.jjcc.2020.12.003 (2021). Sicras-Mainar, A., Sánchez-Álvarez, L., Navarro-Artieda, R. \& Darbà, J. Treatment persistence and adherence and their consequences on patient outcomes of generic versus brand-name statins routinely used to treat high cholesterol levels in Spain: a retrospective cost-consequences analysis. Lipids Health Dis 17, 277, doi:10.1186/s12944-018-0918-y (2018).

7 Huang, T. C., Lee, P. T., Huang, M. S., Su, P. F. \& Liu, P. Y. Higher premature atrial complex burden doi:10.1038/s41598-021-91800-4 (2021).

Loch, A. et al. Generic atorvastatin is as effective as the brand-name drug (LIPITOR( $\left.{ }^{\oplus}\right)$ ) in lowering cholesterol levels: a cross-sectional retrospective cohort study. BMC Res Notes 10, 291, doi:10.1186/s13104-017-2617-6 (2017).

Kesselheim, A. S. et al. Clinical equivalence of generic and brand-name drugs used in cardiovascular disease: a systematic review and meta-analysis. Jama 300, 2514-2526, doi:10.1001/jama.2008.758 (2008).

Corrao, G. et al. Are generic and brand-name statins clinically equivalent? Evidence from a real database. Eur J Intern Med 25, 745-750, doi:10.1016/j.ejim.2014.08.002 (2014).

11 Gagne, J. J. et al. Comparative effectiveness of generic and brand-name statins on patient outcomes: a cohort study. Ann Intern Med 161, 400-407, doi:10.7326/m13-2942 (2014).

12 Romanelli, R. J., Jukes, T. \& Segal, J. B. Compliance after switching from branded to generic statins. Pharmacoepidemiol Drug Saf 23, 1093-1100, doi:10.1002/pds.3630 (2014).

13 Chapman, R. H. et al. Generic and therapeutic statin switches and disruptions in therapy. Curr Med Res Opin 25, 1247-1260, doi:10.1185/03007990902876271 (2009). 


\section{Figure Legends}

2 Figure 1. Data flow diagram.

3 Figure 2. Kaplan-Meier survival analysis of primary endpoint of 2 groups, after propensity 4 score matching. Upper panel started from medication switch date, and lower panel from 5 medication initialization date. $P$ : log-rank test.

6 Figure 3. Laboratory patient-paired difference before and after medication switch date. $P$ :

7 Student's t test.

$8 \quad$ Figure 4. Prescription amount (upper panel) and expense per person (lower panel) of statin 9 use to time for generic rosuvastatin, brand-name rosuvastatin, and brand-name 0 atorvastatin. The red vertical dash line indicates medication switch date: March 3, 2018. 1 
1 Table 1 Clinical matching characteristics for current patient cohort with switch effect of

2 brand-name atorvastatin and generic rosuvastatin use

\begin{tabular}{|c|c|c|c|c|c|c|c|c|c|c|}
\hline & \multicolumn{5}{|c|}{ Before Matching } & \multicolumn{5}{|c|}{ After Matching } \\
\hline & \multicolumn{2}{|c|}{$\begin{array}{l}\text { Rosuvastatin } \\
\qquad(\mathrm{n}=600)\end{array}$} & \multicolumn{2}{|c|}{$\begin{array}{l}\text { Atorvastatin } \\
(\mathrm{n}=2,125)\end{array}$} & & \multicolumn{2}{|c|}{$\begin{array}{l}\text { Rosuvastatin } \\
\quad(n=592)\end{array}$} & \multicolumn{2}{|c|}{$\begin{array}{l}\text { Atorvastatin } \\
\qquad(\mathrm{n}=592)\end{array}$} & \multirow[b]{2}{*}{$\mathrm{p}$} \\
\hline & $\begin{array}{l}\text { mean } \\
\text { (count) }\end{array}$ & $\begin{array}{c}\mathrm{SD} \\
\text { (percentage) }\end{array}$ & $\begin{array}{l}\text { mean } \\
\text { (count) }\end{array}$ & $\begin{array}{c}\mathrm{SD} \\
\text { (percentage) }\end{array}$ & $\mathrm{p}$ & $\begin{array}{l}\text { mean } \\
\text { (count) }\end{array}$ & $\mid \begin{array}{c}\mathrm{SD} \\
\text { (percentage) }\end{array}$ & $\begin{array}{l}\text { mean } \\
\text { (count) }\end{array}$ & $\begin{array}{c}\mathrm{SD} \\
\text { (percentage) }\end{array}$ & \\
\hline Age (year) & 65.15 & 11.82 & 68.54 & 11.79 & $<0.001$ & 65.15 & 11.82 & 65.38 & 12.08 & 0.735 \\
\hline $\begin{array}{l}\text { Body mass index } \\
(\mathrm{kg} / \mathrm{m} 2)\end{array}$ & 26.33 & 5.01 & 25.93 & 5.62 & 0.143 & 26.33 & 5.01 & 25.94 & 4.47 & 0.198 \\
\hline $\begin{array}{l}\text { Median follow up } \\
\text { duration (days) }\end{array}$ & 820 & & 827 & & & 820 & & 822.5 & & \\
\hline Gender (Male) & 316 & $52.67 \%$ & 1228 & $57.79 \%$ & 0.04 & 316 & $53.38 \%$ & 318 & $53.72 \%$ & 0.907 \\
\hline Diabetes mellitus & 363 & $60.5 \%$ & 1144 & $53.84 \%$ & 0.002 & 363 & $61.32 \%$ & 368 & $62.16 \%$ & 0.765 \\
\hline Hypertension & 419 & $69.83 \%$ & 1727 & $81.27 \%$ & $<0.001$ & 419 & $70.78 \%$ & 408 & $68.92 \%$ & 0.486 \\
\hline $\begin{array}{l}\text { Chronic kidney } \\
\text { disease }\end{array}$ & 163 & $27.17 \%$ & 813 & $38.26 \%$ & $<0.001$ & 163 & $27.53 \%$ & 159 & $26.86 \%$ & 0.794 \\
\hline Atrial fibrillation & 58 & $9.67 \%$ & 339 & $15.95 \%$ & $<0.001$ & 58 & $9.8 \%$ & 62 & $10.47 \%$ & 0.7 \\
\hline $\begin{array}{l}\text { Coronary artery } \\
\text { disease }\end{array}$ & 125 & $20.83 \%$ & 853 & $40.14 \%$ & $<0.001$ & 125 & $21.11 \%$ & 133 & $22.47 \%$ & 0.573 \\
\hline Beta-blocker & 176 & $29.33 \%$ & 708 & $33.32 \%$ & 0.066 & 176 & $29.73 \%$ & 184 & $31.08 \%$ & 0.613 \\
\hline $\begin{array}{l}\text { Renin-Angiotensin- } \\
\text { Aldosterone }\end{array}$ & & & & & & & & & & \\
\hline System inhibitor & 234 & $39.0 \%$ & 1016 & $47.81 \%$ & $<0.001$ & 234 & $39.53 \%$ & 246 & $41.55 \%$ & 0.478 \\
\hline Antiplatelet & 237 & $39.5 \%$ & 1286 & $60.52 \%$ & $<0.001$ & 237 & $40.03 \%$ & 305 & $51.52 \%$ & $<0.001$ \\
\hline Anticoagluation & 55 & $9.17 \%$ & 269 & $12.66 \%$ & 0.02 & 55 & $9.29 \%$ & 60 & $10.14 \%$ & 0.624 \\
\hline Laboratory & & & & & & & & & & \\
\hline $\begin{array}{l}\text { Total Choleteroal } \\
(\mathrm{mg} / \mathrm{dL})\end{array}$ & 152.5 & 35.88 & 159 & 42.02 & $<0.001$ & 152.1 & 35.76 & 160.7 & 38.23 & $<0.001$ \\
\hline $\begin{array}{l}\text { Low density } \\
\text { lipoprotein (mg/dL) }\end{array}$ & 86.07 & 29.39 & 92.29 & 34.16 & $<0.001$ & 85.94 & 29.39 & 93.45 & 31.46 & $<0.001$ \\
\hline $\begin{array}{l}\text { High density } \\
\text { lipoprotein (mg/dL) }\end{array}$ & 51.32 & 14.91 & 51.65 & 15.46 & 0.613 & 51.36 & 14.95 & 53.66 & 16.14 & 0.007 \\
\hline Triglyceride $(\mathrm{mg} / \mathrm{dL})$ & 139.6 & 78.52 & 137.6 & 95.14 & 0.512 & 138.4 & 77.11 & 137.4 & 98.65 & 0.788 \\
\hline HbA1c (\%) & 7.45 & 1.32 & 7.14 & 1.35 & $<0.001$ & 7.45 & 1.3 & 7.22 & 1.32 & $<0.001$ \\
\hline $\begin{array}{l}\text { eGFR } \\
(\mathrm{mL} / \mathrm{min} / 1.73 \mathrm{~m} 2)\end{array}$ & 53.22 & 22.35 & 47.94 & 24.97 & $<0.001$ & 53.34 & 22.28 & 51.65 & 25.8 & 0.082 \\
\hline ALT (U/L) & 31.69 & 23.52 & 33.35 & 50.59 & 0.174 & 31.73 & 23.6 & 34.32 & 50.51 & 0.052 \\
\hline
\end{tabular}


1 Table 2. Clinical characteristics before and after matching for current patient cohort with

2 switch effect of brand-name atorvastatin and generic rosuvastatin use

\begin{tabular}{|c|c|c|c|c|c|c|c|}
\hline & \multicolumn{7}{|c|}{ Before matching } \\
\hline & \multicolumn{3}{|c|}{$\begin{array}{l}\text { Rosuvastatin } \\
\qquad(\mathrm{n}=600)\end{array}$} & \multicolumn{3}{|c|}{$\begin{array}{l}\text { Atorvastatin } \\
(\mathrm{n}=2,125)\end{array}$} & \multirow{2}{*}{$\mathrm{P}$} \\
\hline & Before & After & $\begin{array}{l}\text { Patient-paired } \\
\text { difference }\end{array}$ & Before & After & $\begin{array}{c}\text { Patient-paired } \\
\text { difference }\end{array}$ & \\
\hline $\begin{array}{l}\text { Total Choleteroal } \\
(\mathrm{mg} / \mathrm{dL})\end{array}$ & $152.53 \pm 35.88$ & $146.58 \pm 32.99$ & $-4.44 \pm 22.92$ & $159.04 \pm 42.02$ & $\begin{array}{c}154.34 \pm \\
37.65\end{array}$ & $\begin{array}{c}-2.64 \pm \\
25.27\end{array}$ & 0.171 \\
\hline $\begin{array}{l}\text { Low density } \\
\text { lipoprotein (mg/dL) }\end{array}$ & $86.07 \pm 29.39$ & $83.08 \pm 27.88$ & $-2.35 \pm 19.81$ & $92.29 \pm 34.16$ & $89.9 \pm 31.88$ & $\begin{array}{c}-1.57 \pm \\
21.77\end{array}$ & 0.471 \\
\hline $\begin{array}{l}\text { High density } \\
\text { lipoprotein (mg/dL) }\end{array}$ & $51.32 \pm 14.91$ & $49.59 \pm 13.22$ & $-1.2 \pm 7.9$ & $51.65 \pm 15.46$ & $49.38 \pm 14.18$ & $-2.31 \pm 7.36$ & 0.017 \\
\hline Triglyceride (mg/dL) & $139.61 \pm 78.52$ & $136.13 \pm 76.58$ & $-5.66 \pm 49.04$ & $137.56 \pm 95.14$ & $\begin{array}{c}135.05 \pm \\
82.81 \\
\end{array}$ & $\begin{array}{c}-1.37 \pm \\
54.99 \\
\end{array}$ & 0.133 \\
\hline HbA1c (\%) & $7.45 \pm 1.32$ & $7.39 \pm 1.33$ & $-0.05 \pm 0.7$ & $7.14 \pm 1.35$ & $7.07 \pm 1.35$ & $-0.05 \pm 0.68$ & 0.955 \\
\hline $\begin{array}{l}\text { eGFR } \\
(\mathrm{mL} / \mathrm{min} / 1.73 \mathrm{~m} 2)\end{array}$ & $53.22 \pm 22.35$ & $51.55 \pm 23.27$ & $-1.34 \pm 6.94$ & $47.94 \pm 24.97$ & $46.21 \pm 25.81$ & $-1.28 \pm 7.31$ & 0.891 \\
\hline \multirow[t]{4}{*}{ ALT (U/L) } & $31.69 \pm 23.52$ & $31.83 \pm 40.0$ & $-0.48 \pm 20.03$ & $33.35 \pm 50.59$ & $32.22 \pm 73.87$ & $\begin{array}{c}-1.05 \pm \\
28.22\end{array}$ & 0.672 \\
\hline & \multicolumn{7}{|c|}{ After matching } \\
\hline & \multicolumn{3}{|c|}{$\begin{array}{l}\text { Rosuvastatin } \\
(\mathrm{n}=592)\end{array}$} & \multicolumn{3}{|c|}{$\begin{array}{l}\text { Atorvastatin } \\
(\mathrm{n}=592)\end{array}$} & \multirow{2}{*}{$\mathrm{P}$} \\
\hline & Before & After & $\begin{array}{l}\text { Patient-paired } \\
\text { difference }\end{array}$ & Before & After & $\begin{array}{l}\text { Patient-paired } \\
\text { difference }\end{array}$ & \\
\hline $\begin{array}{l}\text { Total Choleteroal } \\
(\mathrm{mg} / \mathrm{dL})\end{array}$ & $152.14 \pm 35.76$ & $146.35 \pm 32.99$ & $-4.38 \pm 23.0$ & $158.19 \pm 43.03$ & $154.45 \pm 38.55$ & $-3.72 \pm 26.95$ & 0.702 \\
\hline $\begin{array}{l}\text { Low density } \\
\text { lipoprotein (mg/dL) }\end{array}$ & $85.94 \pm 29.39$ & $82.94 \pm 27.9$ & $-2.38 \pm 19.89$ & $90.2 \pm 33.95$ & $88.91 \pm 32.35$ & $-2.42 \pm 23.63$ & 0.976 \\
\hline $\begin{array}{l}\text { High density } \\
\text { lipoprotein (mg/dL) }\end{array}$ & $51.36 \pm 14.95$ & $49.62 \pm 13.25$ & $-1.23 \pm 7.93$ & $49.94 \pm 15.3$ & $49.07 \pm 14.38$ & $-1.6 \pm 7.62$ & 0.559 \\
\hline Triglyceride (mg/dL) & $138.41 \pm 77.11$ & $134.93 \pm 75.63$ & $-5.36 \pm 49.02$ & $142.78 \pm 84.98$ & $136.68 \pm 74.73$ & $-5.06 \pm 51.6$ & 0.930 \\
\hline $\operatorname{HbAlc}(\%)$ & $7.45 \pm 1.3$ & $7.37 \pm 1.29$ & $-0.05 \pm 0.7$ & $7.31 \pm 1.44$ & $7.24 \pm 1.49$ & $-0.08 \pm 0.76$ & 0.543 \\
\hline $\begin{array}{l}\text { eGFR } \\
(\mathrm{mL} / \mathrm{min} / 1.73 \mathrm{~m} 2)\end{array}$ & $53.34 \pm 22.28$ & $51.65 \pm 23.25$ & $-1.36 \pm 6.95$ & $50.6 \pm 24.51$ & $48.66 \pm 26.07$ & $-1.37 \pm 8.14$ & 0.988 \\
\hline ALT (U/L) & $31.73 \pm 23.6$ & $31.34 \pm 37.05$ & $-0.58 \pm 19.87$ & $34.75 \pm 56.08$ & $36.27 \pm 118.68$ & $-0.14 \pm 44.92$ & 0.841 \\
\hline
\end{tabular}


1 Table 3.Clinical outcomes between matching treating groups with switch effect of brand-

2 name atorvastatin and generic rosuvastatin use

\begin{tabular}{|c|c|c|c|c|c|}
\hline & \multicolumn{2}{|c|}{ Rosuvastatin (n=592) } & \multicolumn{2}{|c|}{ Atorvastatin (n=592) } & \multirow[t]{2}{*}{$\mathrm{P}^{*}$} \\
\hline & Number & Percentage & Number & Percentage & \\
\hline & \multicolumn{5}{|c|}{ From landmark index date } \\
\hline Median follow up time (day) & \multicolumn{2}{|c|}{820} & \multicolumn{2}{|c|}{822.5} & \\
\hline \multicolumn{6}{|l|}{ Primary } \\
\hline Major cardiovascular adverse event & 16 & $2.70 \%$ & 23 & $3.89 \%$ & 0.265 \\
\hline \multicolumn{6}{|l|}{\begin{tabular}{|l|l|} 
Secondary \\
\end{tabular}} \\
\hline All-cause mortality & 8 & $1.35 \%$ & 11 & $1.86 \%$ & 0.498 \\
\hline Myocardial infarction & 8 & $1.35 \%$ & 10 & $1.69 \%$ & 0.649 \\
\hline Ischemic stroke & 0 & $0.00 \%$ & 3 & $0.51 \%$ & 0.084 \\
\hline & \multicolumn{5}{|c|}{ From statin initiation date } \\
\hline Median follow up time (day) & \multicolumn{2}{|c|}{1803.5} & \multicolumn{2}{|c|}{2359} & \\
\hline \multicolumn{6}{|l|}{ Primary } \\
\hline Major cardiovascular adverse event & 27 & $4.56 \%$ & 39 & $6.59 \%$ & 0.664 \\
\hline \begin{tabular}{|l|} 
Secondary \\
\end{tabular} & 18 & $3.04 \%$ & 23 & $3.89 \%$ & 0.826 \\
\hline All-cause mortality & 8 & $1.35 \%$ & 11 & $1.86 \%$ & 0.706 \\
\hline Myocardial infarction & 18 & $3.04 \%$ & 23 & $3.89 \%$ & 0.826 \\
\hline Ischemic stroke & 2 & $0.34 \%$ & 6 & $1.01 \%$ & 0.255 \\
\hline
\end{tabular}




\section{$1 \quad$ Figure 1}

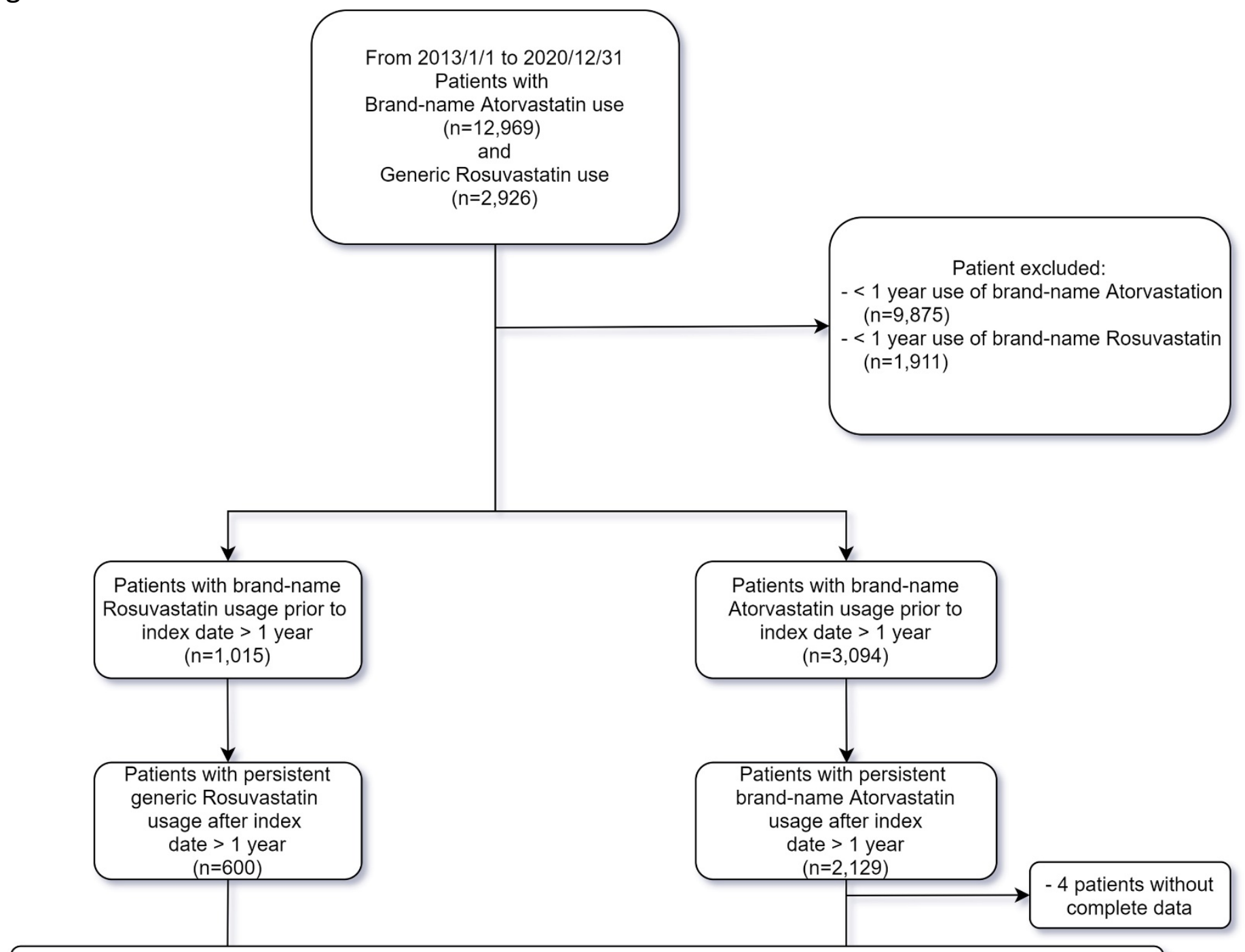

1:1 Propensity Score Match ( age, gender, commobidities) 
1 Figure 2

\section{After medication switch index date}

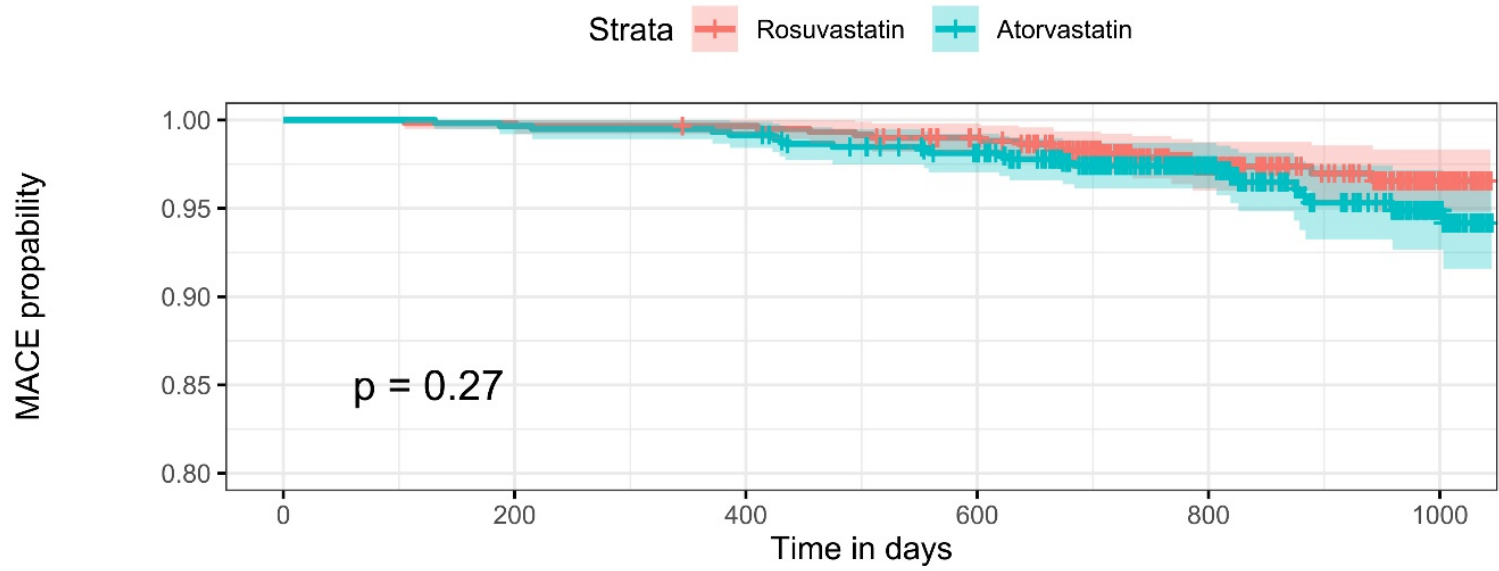

Number at risk

\begin{tabular}{|c|c|c|c|c|c|c|}
\hline \multirow{3}{*}{ 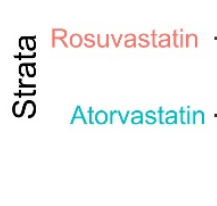 } & 592 & 591 & 589 & 572 & 342 & 152 \\
\hline & 592 & 590 & 587 & 568 & 359 & 138 \\
\hline & 0 & 200 & 400 & 600 & 800 & 1000 \\
\hline
\end{tabular}

\section{After medication initiation date}

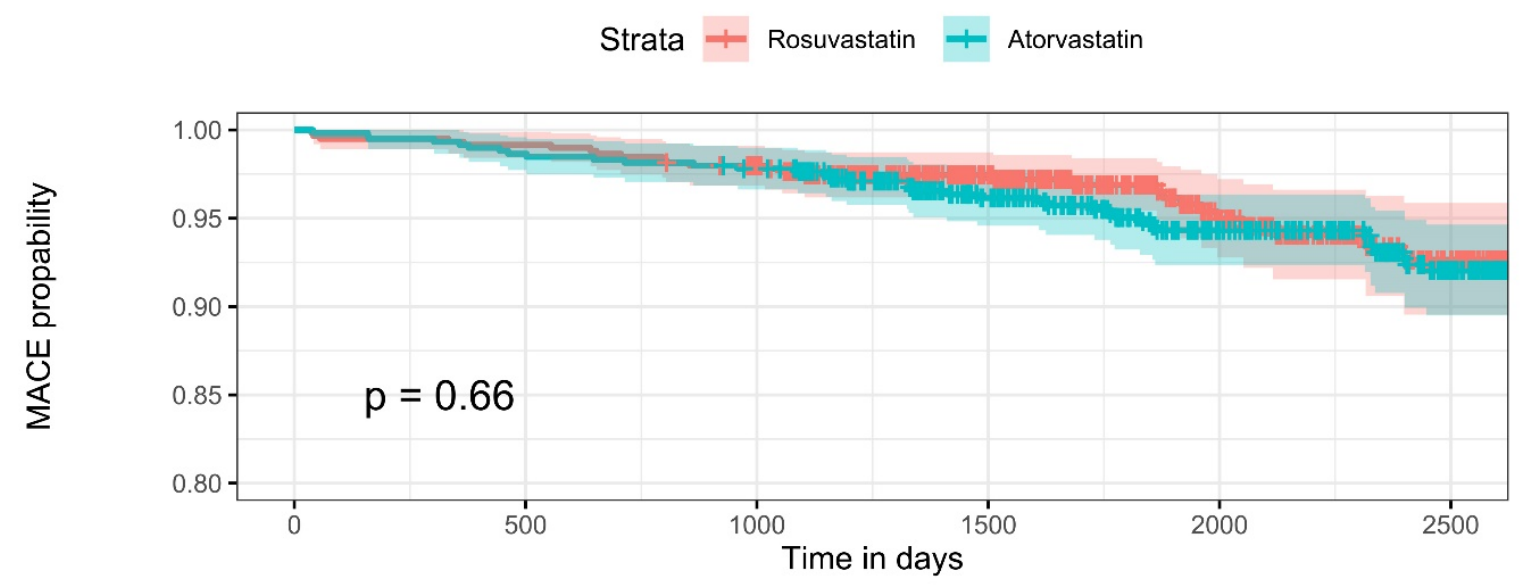

Number at risk

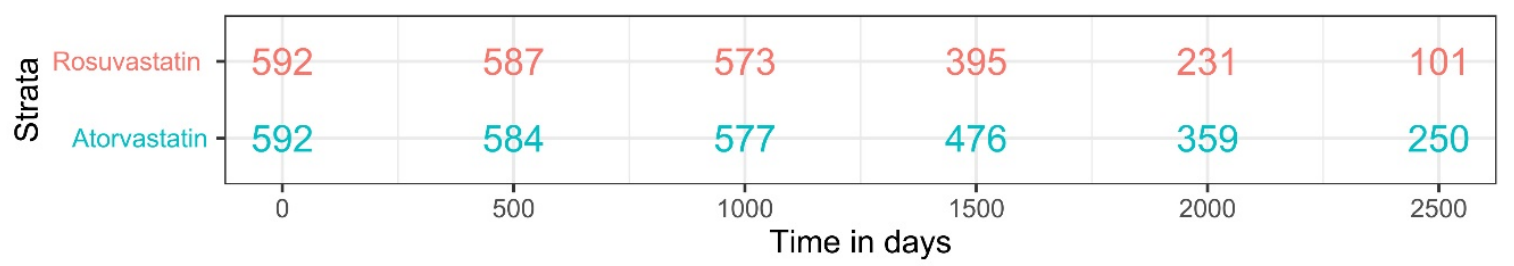




\section{$1 \quad$ Figure 3}

Laboratory Data (Both $n=592$ )

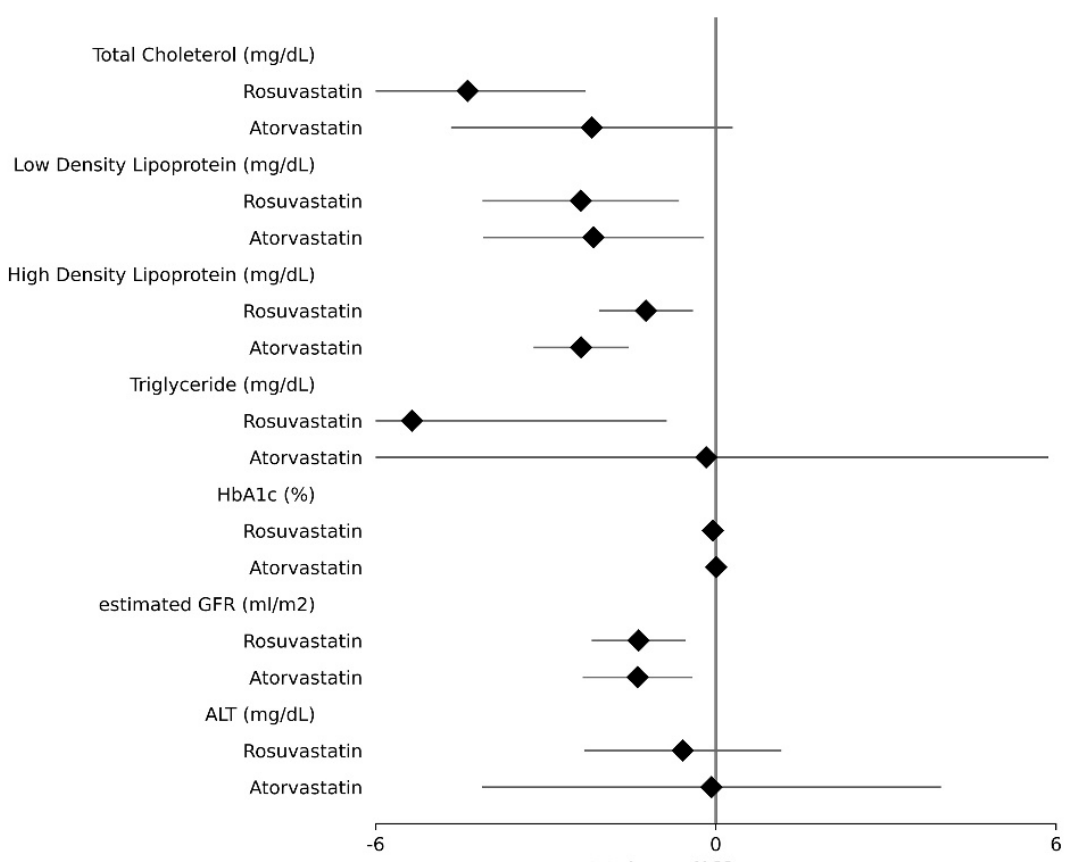

Value difference

Patient-paired difference

$P$ value

$\begin{array}{lcc}\text { Mean } & 95 \% \mathrm{Cl} & \\ -4.376 & (-6.455,-2.298) & 0.181 \\ -2.187 & (-4.672,0.298) & 0.865 \\ & & \\ -2.382 & (-4.116,-0.649) & 0.059 \\ -2.157 & (-4.105,-0.209) & \\ & & 0.169 \\ -1.232 & (-2.06,-0.404) & \\ -2.375 & (-3.215,-1.535) & \\ -5.358 & (-9.85,-0.867) & 0.248 \\ -0.168 & (-6.201,5.865) & \\ & & \\ -0.051 & (-0.119,0.017) & 0.978 \\ 0.007 & (-0.064,0.078) & 0.816 \\ -1.362 & (-2.19,-0.534) & \\ -1.38 & (-2.35,-0.41) & \\ -0.582 & (-2.319,1.155) & \\ -0.075 & (-4.123,3.973) & \end{array}$

2 


\section{$1 \quad$ Figure 4}

\section{Medication Prescription - Time}
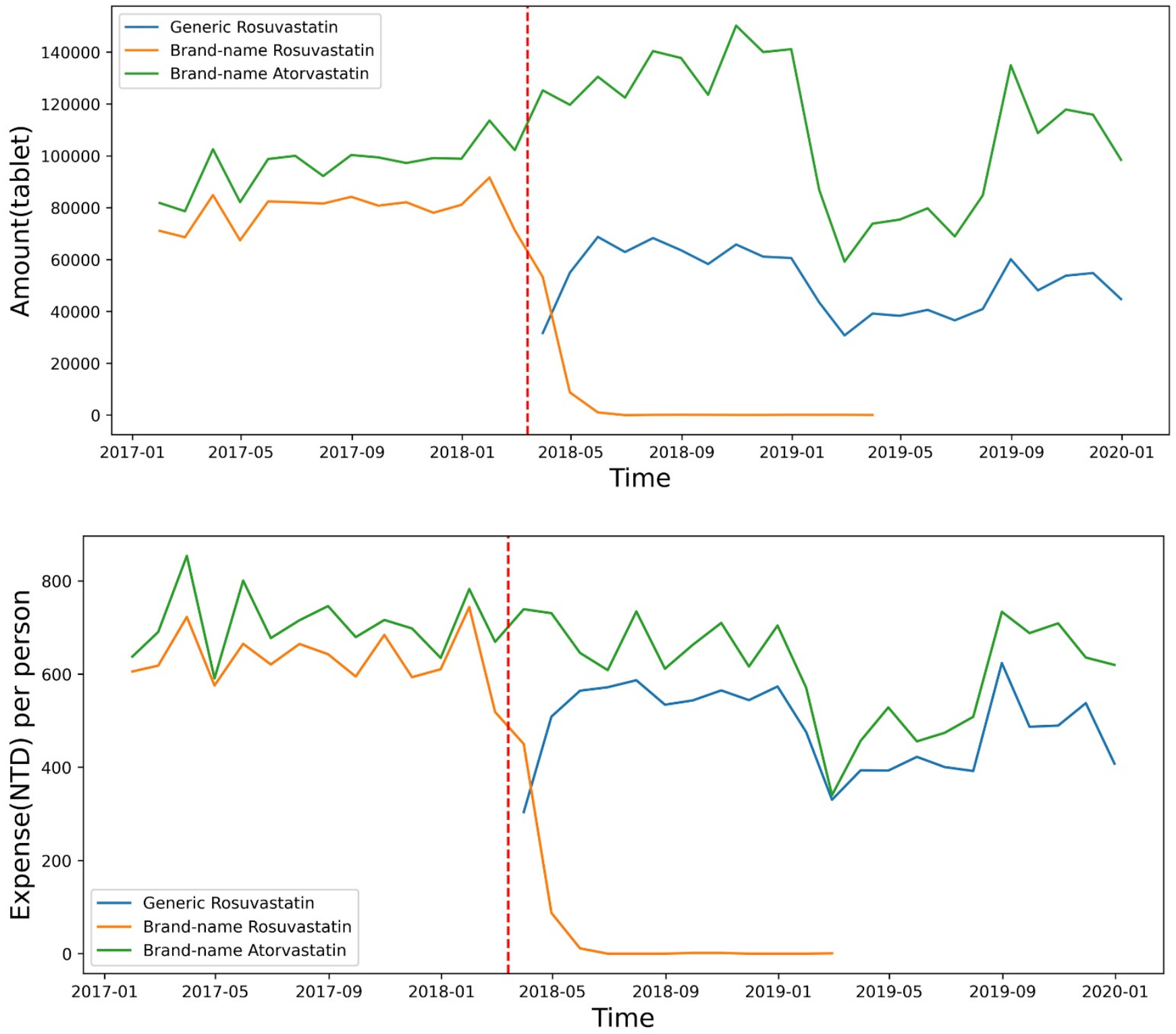